\title{
Emociones juveniles y participación política en jóvenes universitarios de la ciudad de Lima durante los procesos políticos y electorales de los años 2015 y $2016^{1}$
}

\author{
Jerjes Loayza Javier \\ Universidad Nacional Mayor de San Marcos
}

\section{Resumen:}

La investigación parte de las elecciones presidenciales y congresales realizadas en el Perú en el año 2016. Se analizan reflexiones discursivas juveniles universitarias en Lima a través de entrevistas semiestructuradas que profundizan en el significado de la política. Se reconocen críticas a una política inservible o muy negativa que debe ser reestructurada desde sus cimientos para alcanzar una verdadera transformación de la sociedad. La juventud consultada posee una participación activa en el cambio de sus propias instituciones universitarias, por lo cual no dejan de ver en la política una estrategia institucional de cambio y posibilidades; por ello, presentan una concepción renovadora y necesaria. La crítica vertida por los estudiantes entrevistados migraría hacia nuevas resignificaciones de la política en el Perú.

Palabras clave: política, juventud, corrupción, apatía.

\begin{abstract}
:
The research is based on the presidential and congressional elections held in Peru in 2016. University youth discourse reflections in Lima are analyzed through semi-structured interviews that deepen the meaning of politics. Criticisms are recognized of a useless or very negative policy that must be restructured from its foundations to achieve a true transformation of society. The consulted youth has an active participation in the change of their own university institutions, so they do not stop seeing in the politics an institutional
\end{abstract}

1 Investigación realizada como parte del proyecto con financiamiento "Educación, democracia y Nación en el Perú en el siglo XX y XXI", con código E1815150, avalado durante el año 2018 por el Vicerrectorado de Investigación y Posgrado de la Universidad Nacional Mayor de San Marcos. Dicho proyecto se encuentra en el marco del grupo de investigación Estado, Nación y Democracia en el Perú y AmÉRICA LATINA. 
strategy of change and possibilities, for which they present a renewal and necessary conception. The criticism expressed by the students interviewed would migrate towards new resignifications of politics in Peru.

Key words: Politics, youth, corruption, apathy.

\section{Introducción}

La política representa una importante construcción socioteórica que implica la solución de problemas sociales y colectivos. Su caracterización en América Latina se ha vuelto una profesión en manos de hombres y mujeres que, en la inserción partidaria, busca detentar el poder para cambiar y transformar su correspondiente país en beneficio del interés colectivo. Sin embargo, en el Perú, la población no se ha sentido representada, y es negativa la crítica a los presidentes, al Congreso de la República y a toda autoridad representativa. En buena cuenta, ello se debería a los escándalos de corrupción que se han producido en los últimos años. En este contexto, las elecciones representarán un mercado de regateos en donde cada candidato busca atraer carismáticamente los votos, en lugar de ofrecer una propuesta cuerda, posible y clara.

En el contexto de las elecciones presidenciales, se pueden explorar emociones y sensibilidades en torno a la política, dado que se está rodeado del márketing, de las promesas partidarias, de los esfuerzos caudillistas y de todo lo que significa la maquinaria masiva del bombardeo electoral y lo que representa detentar el poder durante cinco ańos. En medio de esta batalla de propuestas personalistas y expectativas colectivas, la población define hacia quiénes derivar su confianza y su voto. En este grupo, encontramos a las juventudes que, en el intervalo entre los quince y veintinueve años, representan, en la ciudad de Lima, al año 2015, al 27,1 \% de la población total de la ciudad, es decir, 2409 385 jóvenes (Senaju, 2015). Sin embargo, en las elecciones municipales 2015-2018, postularon un total de 3462 jóvenes, de quienes se eligieron apenas a 182 (Senaju, 2015). Esta contradicción provoca que la política sea un espacio de poder dirigido, en la mayoría de casos, por una gerontocracia que desconfiará de las juventudes para dirigir el 
país monopolizando todo el espacio. Sin embargo, la juventud, como importante bono demográfico, debería ser vislumbrada como referente de emprendedurismo y de innovación tecnológica, y ser clave para todo Estado.

La investigación formulada se basa en los discursos en torno a la política de la juventud propositiva interesada en cambios y transformaciones sociales. A partir de entrevistas basadas en la experiencia política de sus actores, se entreteje una sistematización y una interpretación que busca refrescar la dinámica teórica en torno a la política, que rebasa toda postura racional y se enrumba hacia una sociología política del cuerpo y de las emociones (Loayza, 2013a). Tal como lo establece Dussel (2006), las instituciones políticas están agotadas, porque atraviesan un proceso entrópico y fetichizado dada la autoreferencia de la que sufren. Este es el rol de la sociología política: criticar los presupuestos teóricos a partir de las cotidianidades ciudadanas que retan toda alusión teórica de corte europeo, racional e institucional.

Es así que nos preguntamos lo que sucede con la política institucionalizada amparada en el poder estatal representativo y en sus instituciones más importantes. Se analiza cómo adecúan y utilizan las categorías políticas la juventud entre dieciocho y veinticinco años de edad de la ciudad de Lima, en la coyuntura de las elecciones presidenciales del año 2016. Se profundiza en lo que sienten cuando perciben el término "política", así como en las críticas y las recomendaciones en torno a esta. Se busca rastrear los prejuicios, las opiniones, los miedos y las conjeturas que se entretejieron en dichas elecciones presidenciales. Además, se reconocen estrategias políticas para afrontar problemas de diversas modalidades en sus organizaciones de origen.

La investigación que se presenta a continuación tiene como método la teoría fundamentada, en la cual el trabajo de campo permite la construcción de losindicadores teóricos y la perfección delos instrumentos de recolección de datos. Asimismo, se aplica el método fenomenológico que profundiza en las motivaciones, las fantasías y los sueños de cada entrevistada y entrevistado. Se aplicaron entrevistas semiestructuradas a dieciséis mujeres y quince hombres de distintos distritos. 
En dicha muestra, se incluyó a jóvenes pertenecientes a organizaciones estudiantiles de universidades públicas y privadas de la ciudad de Lima. Los estudiantes encuestados pertenecen a las siguientes instituciones: Universidad Nacional Mayor de San Marcos, Universidad Nacional de Ingeniería, Universidad Nacional Federico Villarreal, Escuela Nacional de Arte Dramático, Pontificia Universidad Católica del Perú, Universidad Ricardo Palma y Universidad Las Américas. Las entrevistas se realizaron en el intervalo comprendido entre febrero y junio del año 2016, en plena coyuntura de las elecciones presidenciales, puesto que dicho entorno fue propicio para concatenar el interés generalizado (gracias al márketing político, a los debates y a toda la maquinaria electoral que tiene lugar cada cinco años en todo el país), y las categorías políticas más resaltantes, como democracia, representatividad y participación.

\section{Antecedentes}

Un importante hecho que conmovió al planeta fue el de los Indignados que tuvo lugar en España entre los años 2011 y 2012. Gracias a este fenómeno, se analizan las nuevas formas en que los movimientos sociales, en manos de jóvenes manifestantes, desfilan más allá de las fronteras y de los aspectos culturales: las emociones colectivas forman un cuerpo de sentimientos aunados por la crítica a los gobiernos. La juventud, frente a la corrupción y al dogma, habría reaccionado tomando la forma de independencia y, gracias a los académicos, de reformista (Biagini, 2012). Esta "toma de conciencia” se derivaría de la decadencia del sistema político español por el cual la población no se sentía representada, en tanto todo Estado moderno supone ser resultado de la voluntad de cada ciudadano que desea interactuar en una sociedad pacíficamente, dentro de una lógica predecible que deviene de la propia historia (Adrianzén, 2010). Como establece Lechner (2002: 38), "la ciudadanía sí será capaz de movilizarse cuando el estado de cosas existente se vuelva insoportable".

Una herramienta muy innovadora que ha sido utilizada es la edición digital denominada Photoshop para promocionar a los candidatos, las ideologías y el estatus buscado por las personas a través 
de la técnica (Roitman, 2012), con lo cual se rebasan los límites de los partidos políticos tradicionales. La recurrencia de los indignados ha sido mundial, aunque con especificidades en cada país y localidad, con una energía colectiva avasalladora sin precedentes en todos los casos, ya que cuenta con indignados "en cualquier parte del mundo, así en Finlandia como en Noruega, en Italia o en España" (Klein, 2012: 90). De esta manera, las juventudes buscan un protagonismo cada vez mayor, acercándose sincréticamente al ámbito público y al ámbito privado, superando las dicotomías y las polaridades (Agudelo-Ramírez, MurilloSaá, Echeverry-Restrepo, Patiño-López, 2010). Para Castells (2009), se fomentan cada vez más espacios de realidad virtual de sociabilidad, todo al punto de que "comunicar es compartir significados mediante el intercambio de información y la transformación del entorno de las comunicaciones afecta directamente a la forma en que se construye el significado y, por tanto, a la producción de las relaciones de poder" (Castells, 2012: 23-24).

El caso peruano fue muy bien analizado por Enrique FernándezMaldonado (2015) que señala el modo en que las organizaciones juveniles en el año 2014 lograron menguar sus diferencias políticas e inclusive personales, sumando las fuerzas de grupos tradicionales e innovadores. Su vínculo con el movimiento de los "indignados" estuvo basado en las estrategias utilizadas, tales como el uso de las redes sociales: "mientras se cocinaba la aprobación de la Ley, coordinaron entre los núcleos sindicales y colectivos políticos que organizaron las primeras acciones de protesta, logrando captar la atención de otros actores no sindicales" (Fernández, 2015: 126). Las tecnologías de la información y la comunicación propiciarán transformaciones no solo al momento de compartir sus sentires, sino de construir el propio discurso. En el otro extremo no participativo, investigué a jóvenes no organizados en el contexto de las elecciones presidenciales del año 2011, que profundizaban en sus discursos y proponían que la apatía que reflejan sus testimonios no es, en absoluto, sinónimo de rehuir de la política misma, sino de crítica hacia esta (Loayza, 2013b).

Para referirnos a las motivaciones juveniles, apuntaremos hacia sus subjetividades colectivas, las cuales se entenderán como "todas las 
acciones, enunciaciones, discursos de reconfiguración y autoafirmación de la idea de sí mismo, especie de anclaje identificatorio que se evidencian en expresiones, construyendo el sentido de la vida" (López, 2011: 17). Es importante identificar "en las prácticas discursivas (aparentemente banales, cotidianas, superficiales) elementos explicativos que permiten dar cuenta de la importancia de la subjetividad en términos del andamiaje de lo público" (González, 2012: 155). Por ello, se decide partir de una noción del poder menos exclusiva y más propicia a la cotidianidad y a las intersubjetividades.

En este contexto de incesantes cambios, Aguilera (2012), al momento de explicar el comportamiento de los estudiantes de secundaria que se movilizaron en Chile, permite comprender el choque entre enfoques antiguos de pensar la política desde el Estado centrado en demandas, es decir, en un repertorio "antiguo", mientras que los jóvenes chilenos se "apuntaban a un conjunto de preocupaciones de orden 'relacional' entre autoridades y estudiantes, respondiendo a un repertorio 'nuevo' o emergente” (Aguilera, 2012: 104). Este desfase es palpable en países como Chile, en donde el padrón electoral ha envejecido y ha dado lugar a una automarginación juvenil: "las razones que han motivado esta conducta se fundamentan en un descontento con la política y con los actores que la ejercen" (Araya-Castillo y Etchebarne, 2014: 238).

De esta forma, en América Latina, los jóvenes "aspiran a crear normas y leyes que les permitan salir de las condiciones de miseria y atraso sin dejar su cultura y su forma de organización: aspiran a ser tomados en cuenta como iguales entre diferentes" (Piñeyro, 2013: 48). Podemos concluir, entonces, la necesidad repensar la formación de las y los jóvenes, a partir de la nueva cultura juvenil que se está gestando y en diálogo con el contexto en el que están inmersos. Es necesario hacerlo teniendo en cuenta a cada uno en su originalidad, su historia personal y social, "reconociendo la posibilidad que tienen de asumirse como personas dueñas de su libertad, capaces de comprometerse con el mundo en que viven" (Carena, Pisano y Tessio, 2009: 31). 


\section{Concepciones juveniles acerca de la política}

Para conocer el modo en que la política cobra significados diversos que no necesariamente van en relación directa con sus conceptos clásicos modernizantes propios de una concepción europea y racional, la posibilidad preguntar a los jóvenes qué es la política para ellos permite un concepto más cultural y emocional, antes que teórico y racional; un concepto que se traduzca en cotidianidades y vivencias directas a partir de las sensaciones que esta produce en los miembros de una sociedad.

Partimos del caso de jóvenes que se encuentren participando activamente en alguna organización, como es el caso de A. L., quien a sus 20 años mantiene una posición propositiva en su distrito. Él no solo defiende una propuesta diferenciada de las dimensiones negativas de la misma en torno a la corrupción y al clientelaje, sino que plantea una visión de la política capaz de construir mejoras en la sociedad: La politica se ha vuelto una herramienta muy poderosa para tomar decisiones y realmente merece mucha atención de lo que se toma, pues es quizás la mayor expresión del hombre para cumplir con los fines nobles en beneficio de la comunidad ${ }^{2}$.

El caso de una estudiante ${ }^{3}$, a partir de cuya experiencia política estudiantil, nos permite comprender mejor la dicotomía que conviven en el significante subjetivo de la política: "Desde la universidad, se suelen tener dos visiones de la politica: la politica universitaria en muchas maneras idealizada y la politica nacional, la real, mayormente vilificada y desahuciada." Asimismo, afirma la dificultad para convivir junto a la política, debido a las implicancias de las situaciones de corrupción: "convive tan institucionalmente con la corrupción que [...] disuade a la mayoria de personas honestas de incursionar en ella y crea un ambiente en el que incluso las personas que no desean hacerlo, terminan aprovechando sus cargos para beneficio propio, por el simple hecho de que es dificil no embarrarse en este ambiente".

2 A. L. es un hombre de 20 años de edad. Trabaja en la Municipalidad de Miraflores y estudia Gerencia de Desarrollo Humano.

3 E. es mujer, tiene 20 años y vive en Pueblo Libre. Estudia Sociología en la Pontificia Universidad Católica del Perú 
Encontramos que las percepciones van entre dos polos diferenciados, pero complementarios: aquellas que solo tienen palabras de crítica a la política y aquellas que manifiestan su necesario y vital rol en nuestras vidas. De manera neutral, habrá quienes se limiten a conceptuar la política sin ánimo de tomar iniciativa ofensiva o defensiva de la misma, aunque dejarán en claro la necesidad de conocer y practicar dichas ciencias. Un testimonio se limitará a conceptuar la política de la siguiente manera: "es el simple hecho de querer cambiar las cosas en el Estado o gobierno de nuestro entorno, es impulsar desde la agencia de cada uno y desde sus propias motivaciones mejoras para la sociedad"'.

Otros representantes estudiantiles señalarán que la política se convierte en un gran atractivo para cierto grupo de personas que actuarán de manera egoísta desnaturalizando el concepto mismo de lo que debería ser. S. C. establece lo siguiente: "Es una herramienta necesaria pero desprestigiada para tomar decisiones y efectuarlas desde un nivel de bases a los niveles más altos de decisión" 5 . Por su parte, T. analiza la política como una práctica hegemónica negativa: "Creo que este sistema te empuja a no hacer política. La politica que se hace la hacen pocas personas. La poca politica que pocas personas hacen está ensuciada con objetivos económicos de sectores concretos de la sociedad"6. Las opiniones de los jóvenes entrevistados en esta sección dejan muy en claro que la política no solo es importante, sino que "define el rumbo de nuestra sociedad con decisiones que impactan a todos"

Ahora bien, otro grupo de testimonios nos acerca a la política como necesidad más que como posibilidad. Entiéndase que con necesidad se desea establecer que, a pesar de lo nefasta que pueda ser, es una práctica necesaria. Acaso esta sería una sentencia sencilla, pero

4 R. es hombre, tiene 19 años, vive en Pueblo Libre y estudia Sociología en la Pontificia Universidad Católica del Perú.

5 S. C. es hombre, tiene 25 años, vive en San Miguel y estudia Sociología en la Universidad Nacional Mayor de San Marcos.

6 T. es hombre, tiene 21 años, vive en Jesús María y estudia Sociología en la Pontificia Universidad Católica del Perú.

7 X. J. N. es hombre, tiene 25 años y vive en Chaclacayo. Estudió Gestión de Proyectos en Ingeniería. Es profesor universitario. 
EMOCIONES JUVENILES Y PARTICIPACIÓN POLÍTICA EN JÓVENES UNIVERSITARIOS DE LA CIUDAD DE LIMA DURANTE LOS PROCESOS POLÍTICOS Y ELECTORALES DE LOS AÑOS 2015 Y 2016

significativa: "la politica es frustrante, es atractiva pero no deja que se le ame completamente" ${ }^{8}$. Ello es posible en tanto que la contingencia y la pérdida de control pueden provocar niveles críticos de estrés colectivo. Para comprender su aspecto negativo, una estudiante señala que la práctica política "está contaminada por malos políticos que buscan en primer lugar sus beneficios sin importarles que están representando al pueblo y que su labor debería dedicarse al bienestar de nuestra sociedad'?. Para otro estudiante, "en la politica de nuestro pais abunda la corrupción es por ello que no progresamos como tal"10. Los comentarios expuestos entenderán la política como un aspecto externo, ajeno e impersonal.

Por ejemplo, otra entrevistada sostiene que "actualmente estamos mal politicamente debido a las malas decisiones tomadas por nuestros gobernantes" 11 . La corrupción carcomerá todo a su alcance, inclusive a quienes se esfuerzan por lo mejor: "en mayor parte tengo una visión negativa debido a la corrupción, falta de carácter y la ausencia de transparencia en la politica. Aunque hay pocos que hacen bien su trabajo en su mayoría es muy torpe y decepcionante"12. En este aspecto, es importante destacar que ninguno de los entrevistados y ninguna de las entrevistadas posee un cargo político estudiantil, lo cual tiene directa relación con su opinión negativa de la política. En esta línea, una estudiante establece que la política persigue la voluntad de caudillos populistas, y da lugar a una serie de eventos negativos y frustrantes para el Perú. ${ }^{13}$

8 B. B. R. es mujer, tiene 19 años, vive en La Victoria y estudia Sociología en la Universidad Nacional Mayor de San Marcos.

9 X. N. E. es mujer, tiene 18 años y vive en Pachacamac. Estudia Trabajo Social en la Universidad Nacional Federico Villarreal.

10 X. N. es hombre, tiene 24 años y vive en Lurín. Estudia Derecho en la Universidad Las Américas y trabaja en un restaurante.

11 E. es mujer, tiene 20 años y vive en Surco. Estudia Ingeniería Civil en la Universidad Ricardo Palma.

12 G. R. es mujer, tiene 18 años y vive en San Juan de Lurigancho. Estudia Arquitectura en la Universidad Ricardo Palma.

13 M. B. P. es mujer, tiene 21 ańos y vive en San Juan de Lurigancho. Estudia Traducción e Interpretación en la Universidad Ricardo Palma. 
El Perú es el escenario de la desafección y del nihilismo en torno a la política y, con ella, de la esperanza y la posibilidad de mejora. C. F. nos ayuda a entender que el desinterés en la política radica en la frustración inicial que anotábamos, dada su penosa práctica: "Considero que no sé mucho o casi nada de politica y para mí siempre ha sido un tema del cual no me interesa saber; recién el año pasado me llamó la atención y me parece que es un tema muy mal usado en el pais" 14 . Otra estudiante señala lo siguiente: "Opino que en nuestro país no puede haber un gobernador que pueda cumplir todo lo que prometa, mientras existan los grupos grandes de poder, ya que ellos hacen y deshacen a los candidatos" 15 .

Para concluir con este grupo de testimonios que critican la política sin posibilidad de mejorarla, otra estudiante no duda en señalar que la política se convierte en vehículo egoísta de beneficios individuales, y se enajena como concepto y como práctica previa: "es muy lamentable, puesto que las personas que logran obtener un cupo en la politica olvidan la función que ellos tienen que cumplir, buscando asi el beneficio propio olvidando a los ciudadanos del pais" ${ }^{16}$. Destacamos nuevamente que las opiniones vertidas son claras: no hay lugar a una transformación de la sociedad, dado que el orden de dominación viene desde arriba. Es destacable que casi ninguno de los entrevistados aludidos ha incursionado en una práctica organizacional. Sin embargo, ello no desmerece, en absoluto, que sus opiniones reflejen un sentimiento y evoquen una emoción muy profunda: la tristeza y el desencanto en torno a la política. Precisamente, se han planteado, desde la academia, enfoques que toman esta perspectiva a partir de la apatía y del desencanto como indicadores claramente políticos que le otorgan una clara importancia a dichas emociones juveniles: "El campo politico tiene que ver con lo que se tematiza en la vida diaria, con las posturas que los sujetos adoptan frente a aquello que los interpela" (González, 2012: 155).

14 C. F. es mujer, tiene 24 años y vive en Barranco. Estudia Pedagogía Teatral en la Escuela Nacional de Arte Dramático.

15 L. B. es mujer, tiene 18 años, vive en Lurín y estudia Ingeniería Civil en la Universidad Ricardo Palma.

16 X. N. E. es mujer, tiene 18 años y vive en Pachacamac. Estudia Trabajo Social en la Universidad Nacional Federico Villarreal. 
Otros testimonios implican la necesidad de una acción política en la sociedad, a pesar de lo negativa que pueda ser. Por ejemplo, un joven dirigente del partido Patria Roja deja la política en manos de quienes la ejercen, ya que dependerá de ellos el modo en que se desenvuelva: "Que la politica es un medio de trabajo, una forma de vida, es el arte de poder gobernar, un servicio a la comunidad, opino también que depende mucho de las personas que ejercen la politica si estos hacen una buena labor; entonces, esta será buena en todos sus ámbitos" ${ }^{17}$. Lo resaltante aquí es la capacidad del joven dirigente de amalgamar cuatro aspectos: trabajo, forma de vida, arte y servicio. Ello nos llama a pensar la política como agencia de poderosa magnitud en aquellos quienes la ejercen, lo cual no los avasalla ni debilita.

Un estudiante, además de formar parte de una banda de rock, reitera que la política tiene grandes posibilidades de cambio, pero "es un camino fácil para adquirir poder y beneficios personales" 18 . La vocación y la ambición son dos formas de sentirse comprometido con algo, ya sea individual o colectivo, pero emociones al fin y al cabo, como lo señala otra entrevistada: "la politica es una actividad que se debe hacer por vocación, ayudando a tu pais en todo ámbito pero actualmente se ejerce por ambición. Eso hace que las personas violen sus principios y ensucien la actividad politica, desanimando a los más jóvenes a incursionar en ella"19.

¿Cuán decisivo es el desánimo en la juventud para practicar una política distinta y transformadora? O más aun: ¿̧hasta qué punto la crítica y negación de la política no implica la rehabilitación de una política cargada de indignación y crítica social? Para graficar esta perspectiva, veamos cómo una estudiante separará aquello que es de aquello de lo que estipula su concepto primigenio y primordial: "pienso

17 X. A. P. es hombre, tiene 23 años y vive en el Cercado de Lima. Estudió Ciencias Políticas en la Universidad Nacional Mayor de San Marcos. Es presidente del Movimiento de Afirmación Social del distrito de Villa El Salvador y dirigente de las juventudes comunistas del Perú Patria Roja.

18 X. E. U. es hombre, tiene 24 años y vive en Puente Piedra. Estudia Psicología en la Universidad Nacional Federico Villarreal y toca en una banda de rock.

19 G. V. es mujer, tiene 18 años y vive en San Martín de Porres. Estudia Sociología en la Universidad Nacional Mayor de San Marcos. 
que llevada de una forma correcta, está hecha para el beneficio de todo el país" ${ }^{20}$. Otro testimonio plantea que la política es toda práctica cotidiana, cercana y privada. Esta distinción es importante, ya que no deja de señalar que hay una política pública distinta de la que no se lleva del mejor modo:

[...] Es un modo de vida, de estar siempre en crítica y reconstrucción de modos de vivir, de relacionarse con los otros, de llevar tu vida cotidiana con tu pareja, tus amigos, tus compañeros, tu universidad, tu familia. Eso sería para nosotros llevar una "vida política" [...] y en cuanto a la práctica de la política en sí, en el espacio público es un lugar cooptado por gente terrible, megalómanos y con ansias de poder [...] pero siento que es demasiado necesario disputar en este espacio. ${ }^{21}$

Los testimonios que se ofrecerán a continuación están decididamente convencidos de que la política nos compete a todos. $\mathrm{Su}$ necesidad no solo obedece a algo obligatorio, sino a un derecho a decidir y a cambiar para bien nuestra sociedad. K. U. deposita su crítica en torno a la práctica política en las propias personas y no en las instituciones ${ }^{22}$. El poder viene desde las bases o los folículos mismos y no desde arriba, como una mera imposición. La culpa radica en la población, en nosotros mismos. No solo no nos interesan los temas públicos, sino que criticamos a los que se animan a acercarse a dichos ámbitos, acaso del modo en que los testimonios anteriores criticaban sin dar lugar a posibilidades de cambio, puesto que el sistema está predeterminado y destinado al fracaso. J. P. está convencida de que la política opera de manera general y no excluye a nadie, ya que se vuelve una responsabilidad antes que una simple necesidad ${ }^{23}$.

20 K. G. es mujer, tiene 22 años y vive en Surco. Estudia Arquitectura en la Universidad Ricardo Palma.

21 T. es mujer, tiene 21 ańos y vive en La Molina. Estudia Sociología en la Pontificia Universidad Católica del Perú.

22 K. U. es mujer, tiene 22 años y vive en San Juan de Lurigancho. Estudia Derecho en la Universidad Nacional Mayor de San Marcos.

23 J. P. es mujer, tiene 20 años y vive en San Juan de Lurigancho. Estudia Sociología en la Universidad Nacional Mayor de San Marcos. 
A la larga, para los jóvenes partícipes activos en las organizaciones correspondientes en sus universidades, la política no obedece únicamente a un concepto institucional, sino a una forma de comprometerse con algo que trasciende la propia individualidad. Podemos notar que estos testimonios representan un sincretismo entre la noción de lo público y lo privado. Otra estudiante tiene muy claro que la noción política está inserta en cada ser humano desde el inicio mismo de su vida. Inclusive la mera negativa de dicha práctica no querrá decir que nos excluyamos de ella, ya que en la negación subyace una actitud frente a lo público ${ }^{24}$. Ser apáticos frente a lo público nos convierte en víctimas por nuestra propia mano antes que en meras víctimas pasivas. Tal como lo establece X. N. S., la política deberá su complejidad al modo en que conecta tanto a gobernantes como a gobernados en un juego de deberes y responsabilidades mutuo ${ }^{25}$. Para las juventudes organizadas en sus respectivas universidades, la política es parte de su propia naturaleza social, lo que los obliga a tomar una determinada acción frente a la situación que los convoca; de otro modo, terminarían por ser víctimas de su propia inacción: "constantemente es relacionado a la corrupción pero que todos deberíamos intervenir para aportar y dejar de criticar de forma destructiva" 26 .

Cuando se preguntó sobre la posibilidad de regenerar la política en los entrevistados, las respuestas variaron en dos sentidos: los que opinaron que son necesarias mejores personas a cargo de toda responsabilidad política y los que apostaron por intervenir y animar a que el resto de personas que opina negativamente tome las riendas del monstruo político. En la primera perspectiva, hay comentarios diversos que nos permiten dilucidar, en definitiva, un sentimiento crítico y dispuesto a que la situación cambie, aunque no se tenga en claro cómo. Por ejemplo, A. L. señala que es necesario organizarse

24 F. M. A. es mujer, tiene 19 años y estudia Sociología en la Universidad Nacional Mayor de San Marcos.

25 X. N. S. es mujer, tiene 21 ańos y vive en Los Olivos. Estudia Trabajo Social en la Universidad Nacional Federico Villarreal.

26 X. K. T. es mujer, tiene 24 ańos, vive en el Cercado de Lima y es trabajadora social en la Fundación Las Américas. 
con miras a institucionalizar sus propuestas: "Hacen falta líderes con visión de Estado, mas no paternalistas, menos demagogos y sobre todo hacer partidos políticos sólidos para fundar los Planes de Gobierno con visión ideológica” 27.

Las juventudes organizadas en determinados ámbitos esperan cambiar la sociedad de la mano con más personas como ellas. Sin embargo, otros testimonios derivan la responsabilidad a los demás: "Haría falta personas comprometidas con el país y honestas que no piensen en el bien propio, sino en el ajeno" ${ }^{28}$. Más aun, el cambio pareciera estar en el futuro y no en el presente: "nuevas generaciones, nuevas ideas, personas de diferentes disciplinas con sentido, sensibilidad y conciencia social" 29 . Ello deriva en testimonios negativos y difíciles de convencer de esperanza alguna. "Es imposible: el cambio [...] no hace falta que la política se regenere, lo que hace falta es que los hombres y mujeres se regeneren, misión imposible" 30 . La palabra 'imposible' se repite dos veces para quien no hay posibilidad alguna de cambio en la medida que son los hombres y las mujeres los causantes de ello.

Una joven plantea que se necesitan personas cuyos conocimientos estén muy por encima del común: "el ingreso de personas responsables, con un grado de instrucción superior y que sepa enfrentarse a los problemas. Compromiso juvenil para afrontar la problemática política" ${ }^{31}$. Si bien concluye su opinión con la necesaria participación juvenil, pondrá, en primer lugar, una vez más, aspectos técnicos y académicos, y restringirá el campo de la política a quienes la ejercen.

27 A. L. hombre de 20 ańos de edad. Trabaja en la Municipalidad de Miraflores y estudia Gerencia de Desarrollo Humano.

28 X. P. J. es hombre, tiene 20 años y vive en el Cercado de Lima. Estudia Medicina Humana en la Universidad Nacional Mayor de San Marcos.

29 X. K. T. es mujer, tiene 24 años, vive en el Cercado de Lima y es trabajadora social en la Fundación Las Américas.

30 B. B. R. es mujer, tiene 19 años, vive en La Victoria y estudia Sociología en la Universidad Nacional Mayor de San Marcos.

31 X. N. E. es mujer, tiene 18 años y vive en Pachacamac. Estudia Trabajo Social en la Universidad Nacional Federico Villarreal. 
Como establece una estudiante de una universidad privada, serán necesarios "ciertos estándares para los que ocupen los diferentes cargos existentes" 32 ¿Cómo negociar entre los valores y los conocimientos?

Un testimonio aúna dos aspectos: por un lado, exige un filtro que evite el ingreso de personas sin preparación suficiente y, por otro lado, un compromiso moral de parte de aquellos que sean elegidos para tan importante tarea: "un mayor filtro para aceptar a personas a postular a cargos gubernamentales y un sincero compromiso con el desarrollo del país para que los principios de cada partido y trabajador estatal no se desintegren fugazmente" 33 . En esta línea, podemos concluir, con este grupo de testimonios, en los cuales hay una predilección por la moral por encima de otros valores y conocimientos, que debería guiar el camino de los políticos.

Cuando se les preguntó qué es lo que podrían hacer para agenciar o intentar agenciar algún cambio, hubo casos en que los jóvenes participativos sentían la atracción como resultado de un proceso educativo ligado a entornos más cercanos. Ello termina por animarlos a proponer estrategias de mejora colectiva, ya que sentían que su actuar trascendía cualquier decisión personal. T. relata, en su testimonio, la manera en que sería marcado: Mi tío Teodoro me decía que la trascendencia consistía en hacer algo importante para tu sociedad. Y eso no era otra cosa que hacer politica. A los 17 años fui a un taller del partido Tierra y Libertad y me enamoré de lo que hacian. ${ }^{34} \mathrm{~T}$. tuvo la posibilidad de ver muy de cerca qué era la política partidaria, con lo cual define buena parte de su juventud hasta el día de hoy.

El caso de otra joven es muy importante, puesto que, a través de su experiencia, toma el espacio urbano a partir de una protesta de suma importancia para el Perú: la marcha contra el régimen laboral juvenil en el año 2014. A partir de aquel momento, sintió que la política aunaba a cada miembro de un modo colectivo:

32 G. R. es mujer, tiene 18 años y vive en San Juan de Lurigancho. Estudia Arquitectura en la Universidad Ricardo Palma.

33 G. V. es mujer, tiene 18 años y vive en San Martín de Porres. Estudia Sociología en la Universidad Nacional Mayor de San Marcos.

34 T. es hombre, tiene 21 años, vive en Jesús María y estudia Sociología en la Pontificia Universidad Católica del Perú. 
La "marcha contra el nuevo régimen laboral juvenil" fue la primera a la que asistí. Ya había asistido a unas anteriores pero dentro de la universidad. Fue una experiencia bastante grata, sentí que era parte de algo grande, sentí que las personas se habían cansado y estaban en las calles para reclamar sus derechos, sentí que podíamos cambiar las cosas... Me sentí muy bien ${ }^{35}$.

La lucha contra la injusticia en aquella marcha representaba la apertura contra el adultocentrismo, es decir, contra la maquinaria que organizaba la sociedad y condenaba a las juventudes como meros receptores pasivos. A decir de Vásquez (2010), esta visión negaría el reconocimiento de manifestaciones juveniles distintitas para vivir y experimentar la vida, además de que "las deslegitima con el propósito de evitar las emergentes expresiones contra hegemónicas” (Vásquez, 2010: 48). Para este investigador, el adultocentrismo impulsa una "correcta" manera de ver el mundo y de insertarse en él. Esta inserción obliga a acatar la lógica del mercado del consumo y de la producción para luego culpar a la juventud de una "fiebre consumista".

El caso de otra estudiante expresa, en efecto, el modo en que esta marcha no solo generó el reflejo de un descontento, sino la "semilla" de un ejercicio ciudadano que vincula al individuo con un compromiso político lejano del desencanto y de la apatía:

Yo fui, bajamos, nos juntamos con gente de la PUCP, marchamos con la gente de la PUCP, la verdad es que me pareció una marcha superpacifica, hasta creo que por Áncash, por Abancay, nos tiraron lacrimógenas, me confundi. Si yo siento que hubo una semilla, siento que hay esperanza, y eso es lo más importante. El problema es cómo analizas eso. Yo creo que hay varias cosas que se pueden copiar o imitar, y creo que "podemos" es una buena praxis politica. ${ }^{36}$

35 K. U. es mujer, tiene 22 años y vive en San Juan de Lurigancho. Estudia Derecho en la Universidad Nacional Mayor de San Marcos.

36 X. S. S. es hombre, tiene 22 años y estudia Ciencias Políticas en la Pontificia Universidad Católica del Perú. 
De esta manera, nos damos cuenta de la importancia que cobra analizar la protesta juvenil a partir de la "idea de la centralidad de un Estado desplazado" (García, 2014: 66), es decir, que comprende el rol que el Estado posee como "espacio crucial en la disputa con las prácticas y los efectos de poder de las tecnologías gubernamentales que imponen o quisieran imponer las lógicas del mercado" (García, 2014: 66). Asimismo, las participaciones en las marchas y las protestas podrán ser producto de la integración de sus miembros sin que necesariamente haya un conocimiento profundo de los objetivos más lógicos o las valoraciones éticas de aquellas.

\section{Conclusiones}

Se ha partido de una noción de la política más amplia y menos exclusiva, así como de una perspectiva más cultural que únicamente de dominación. A partir de ello y de la mano de un estado de la cuestión que nos remite a un análisis más comprensivo que sea capaz de aunar las diferentes y múltiples miradas juveniles sobre la política, se ha planteado una exploración de lo que esta última representa para la juventud universitaria. En este contexto, se ha elegido tanto a jóvenes comprometidos organizacionalmente con el cambio colectivo como a otros dedicados a sus estudios y a su propia cotidianidad. A partir de ello, podemos acercarnos a diversas conclusiones, entre las cuales destacaremos las siguientes:

1. No puede hablarse de una polaridad entre la apatía y el compromiso político juvenil. Ambas perspectivas parten de una crítica hacia la manera tradicional de hacer política, por lo cual antes que separarse deben integrarse para obtener resultados más complejos y productivos que puedan estudiar el fenómeno juvenil participativo.

2. La juventud organizada entrevistada se siente llamada al cambio y a la transformación, porque parte siempre de una posición muy intersubjetiva y llama a la colectividad a formar parte de un cambio masivo. No se puede percibir lejos de la cosa pública, sino 
muy inserta en dinámicas políticas críticas que buscan un mayor beneficio para la sociedad.

3. La juventud no organizada que percibe la política como algo negativo o muy difícil de cambiar apuesta por una perspectiva alejada de la tradicional, la niega en todo momento y propone una mejor preparación moral y profesional. Sin embargo, no se ve inserta en dicho cambio y propicia la tecnificación de la política, antes que una política que parta de sus propias manos.

4. Se aprecia una relación en tres aspectos: uno primero en torno a jóvenes entre los 18 y los 20 ańos que desean un cambio a partir de una mejor preparación, mejores valores y rigidez normativa; un segundo ámbito de jóvenes entre 20 y 25 años que plantean cambios diferentes de los tradicionales a partir de cotidianidades comunes y sencillas sin que sean únicamente institucionales; y un tercer y último ámbito que pertenece a jóvenes comprometidos, bien en partidos políticos o bien como profesionales del tema, que vislumbran el ejercicio político, sobre todo de manera institucionalizada.

Los tres aspectos, antes que a una mera clasificación, responden a necesidades distintas: jóvenes que empiezan a vincularse con dinámicas organizativas universitarias, jóvenes comprometidos con cambios y dispuestos a proponer dinámicas menos rígidas y más integradoras, y jóvenes que apuestan por la carrera política institucional que, si bien radican en la tradición política dicotómica del Estado frente a la sociedad civil, se caracterizan por poseer un ímpetu muy importante que cabe resaltar, dado que se encuentran convencidos del cambio que pueden propiciar.

5. Existe una economía de las emociones y los sentimientos que lleva a la juventud a evitar el tema político para soslayar el sufrimiento que representa el engaño y la traición que implica la política tradicional. La misma economía se puede notar en quienes han decidido ser parte de prácticas políticas más horizontales, con la diferencia de 
que deciden enfrentar dichos sentimientos fortalecidos por una esperanza colectiva, organizada y potenciada por otros como ellos. Se sienten acompañados y cada paso que darán será plural.

6. La investigación planteada dilucida un necesario acercamiento de voluntades y de emociones intersubjetivas para entender la política en el discurso y en la cotidianidad. Se propone renovar los enfoques clásicos e incorporar el cuerpo y las emociones en el análisis de lo que la política es y lo que puede llegar a ser en la práctica común y corriente de muchos jóvenes en sus correspondientes espacios, a pequeńa, pero muy fortalecida, escala.

\section{Referencias}

ADRIANZÉN, A. (2010) "El regreso del Estado". En El Estado en debate: múltiples miradas. Lima: PNUD.

AGUDELO-RAMÍREZ, A., MURILLO-SAÁ, L., ECHEVERRYRESTREPO, L. \& PATIÑO-LÓPEZ, J. A. (2013). "Participación ciudadana y prácticas políticas de jóvenes en la cotidianidad”. En Revista Latinoamericana de Ciencias Sociales, Niñez y Juventud, 11 (2), pp. 587-602.

AGUILERA, Oscar (2012) "Repertorios y ciclos de movilización juvenil en Chile (2000-2012)”. En Utopia y praxis latinoamericana $\mathrm{N}^{\circ}$ 57. pp. 101-108.

ARAYA-CASTILLO, Luis y Soledad ETCHEBARNE (2014). "Personalidad de marca de partidos Políticos: Una mirada desde la comunidad estudiantil universitaria”. En Revista Latinoamericana de Ciencias Sociales, Niñez y Juventud, 12 (1), pp. 225-241.

CASTELLS, M. (2012) Redes de indignación y esperanzas. Madrid: Alianza Editorial.

Editorial.

(2009). Comunicación y poder. Madrid: Alianza 
CARENA, S., PISANO, M. y TESSIO, A. (2009) Ser joven en América Latina a comienzos del tercer milenio. En Diálogos Pedagógicos No 13. pp. 13-33.

DUSSEL, Enrique (2006) 20 tesis de politica. México D.F.: Siglo XXI.

FERNÁNDEZ-MALDONADO, Enrique (2015) La rebelión de los pulpines. Lima: Otra mirada.

GARCÍA, Hernán (2014) El Estado según Foucault: soberanía, biopolítica y gubernamentalidad (2000-2012). En Utopia y praxis latinoamericana $\mathrm{N}^{\circ}$ 57. pp.53-66.

GONZÁLEZ, J. I. I. (2012). “(De)construyendo la esfera pública. Juventud y (la otra) cultura política”. En Revista Latinoamericana de Ciencias Sociales, Niñez y Juventud, 10 (1), pp. 147-157.

KLEIN, Oliver (2012) "El movimiento de los indignados". En El Cotidiano No 173. pp.89-98.

LECHNER (2002) Las sombras del mañana. La dimensión subjetiva de la política. Santiago de Chile: LQM Ediciones.

LOAYZA (2013a) "Avances teóricos en torno a una epistemología del cuerpo, las emociones y lo político". En Revista Austral de Ciencias Sociales. No 24. pp. 51-69.

-(2013b) “QQué dicen los y las jóvenes acerca de la política? Acerca de los discursos en referencia a la política”. En Roberto Rodríguez (ed.) Movimientos juveniles en América Latina y El Caribe. pp. 217-231.

LÓPEZ, Manuel (2011) "Producción y expresión de la subjetividad en la juventud contemporánea". En Revista de la Facultad de Trabajo Social UPB N $\mathrm{N}^{\circ} 27$. pp. 12-21. 
PIÑEYRO, Carlos (2013) "La otra democracia: la autonomía como alternativa política en América Latina". En Utopía y Praxis Latinoamericana $\mathrm{N}^{\circ}$ 63. pp.33-48.

ROITMAN, M. (2012) Los indignados. El rescate de la politica. Madrid: AKAL.

Secretaría Nacional de la Juventud - SENAJU (2015) Población juvenil en el Perú, cifras regionales 2015. Lima: Autor. Recuperado de: $<$ http://juventud.gob.pe/media/publications/poblacion-juvenilen-el-peru.pdf>

VÁSQUEZ, Jorge (2010) "Subjetividades juveniles y discurso del éxito. Entre la emancipación y la institucionalización de las prácticas”. En Anuario Electrónico de Estudios en Comunicación Social "Disertaciones" No3 Recuperado de: <http://erevistas.saber.ula. ve/index.php/Disertaciones/> 